\title{
Report by Swiss Federal Councillor Adolf Ogi on the results of the Consortium's first conference to the EAPC-D in Brussels, Belgium, on 18 December 1998 *
}

During the EAPC Meeting of Defence Ministers of 12 June 1998, US Secretary of Defence Cohen proposed the creation of a PfP Consortium of defence academies and civilian institutes of security studies. This Consortium should serve to strengthen defence civilian and military professionalism through enhanced institutional cooperation among the forty-four EAPC member states in defence education and training. Its activities should include an annual conference, a dedicated Internet website, a secretariat, and a journal or other appropriate publication to further its goals.

The Federal Republic of Germany cosponsored this proposal and agreed to the establishment of an Interim Secretariat at the George C. Marshall European Center for Security Studies in Garmisch-Partenkirchen. The group of forty-four Defence Ministers at the EAPC meeting welcomed the initiative.

In support of this initiative, Switzerland proposed that the Consortium's first conference be conducted in conjunction with the already planned 'Third International Security Forum,' to be held on 19-21 October 1998 in Zürich as part of the Swiss-sponsored PfP activities. This proposal was welcomed. The George C. Marshall European Center for Security Studies and the NATO Defence College were subsequently invited to serve as co-sponsors and co-organisers.

The combined Third International Security Forum and First Conference of PfP Consortium had a participation of 330 representatives from 45 countries, with representatives from over 150 institutions engaged in European security affairs. 125 persons took part in the PfP Consortium's dedicated workshop, including 85 representatives from 42 EAPC countries designated by their government.

There was strong support for the future development of the Consortium. The participants considered the way ahead for the Consortium, in particular its tasks, procedures and activities. This resulted in the definition of practical objectives in keeping with the original aims outlined for the Consortium. Expert groups were commissioned to meet and develop further options for implementation. The future work will concentrate on three issues: process building, the achievement of practical progress, and networking.

- In the area of process building, virtually all participants viewed the Consortium as a promising co-operative arrangement of national institutions that perfectly matches the spirit of PfP, offering a unique opportunity to foster meaningful cooperation be-

This status report concerning the Partnership for Peace Consortium of Defence Academies and Security Studies Institutes was presented by Federal Councillor Adolf Ogi, Head of the Federal Department of Defence, Civil Protection and Sports (Switzerland), at the Meeting of the Euro-Atlantic Partnership Council in Defence Ministers Session, Brussels, 18 December 1998. 
tween academies, institutes, and experts in security and defence affairs. The Consortium shall develop its own distinct character, and its activities should complement, though not duplicate already existing ones. Agreement was reached on having an annual conference, allowing for personal contacts, dedicated exclusively to Consortium issues. This annual conference shall be held on a rotating basis in interested countries and be conducted in four languages: English, French, German, and Russian. The group of designated attendees from each nation served as an initial co-ordinating committee. Two interim sub-committees were established. The first shall develop ideas for establishing 'membership' or participation in the Consortium through affiliate relationships. The second interim sub-committee shall refine options concerning the tasks (e.g., maintaining contact to members, distributing information and supporting countries or institutions hosting conferences and workshops), location, and staffing of the Consortium's permanent secretariat.

- In the area of practical progress, consensus was reached in support of cooperative, coordinated and joint efforts to share curricula and teaching materials, guest speakers, and faculty members. Prospects for a professional Consortium scholarly journal, issue papers, and/or occasional papers were deemed to be options to be taken up at the next annual conference. Pending a decision on the structure and locations of the Consortium's secretariat, the George C. Marshall European Center for Security Studies was requested to elaborate a proposal to further define the tasks, structure, legal and financial basis of the Consortium. At the Zurich conference, it was felt that it might be useful to establish working groups on security, defence, educational, and other related matters. The introduction of these working groups' results to the plenary of the Consortium would be an important element of the annual conference.

- The employment of modern information technology is very important for maintaining the network character of the Consortium. A dedicated website allowing on-line work, and, possibly later, an electronic journal can play an important role in supporting the connection between institutes, academies, and alumni. The largest potential for future synergy and economy of resources to emerge in this area was an agreement between the Swiss-sponsored, Internet-based International Relations and Security Network (ISN) and the US Defense Department's Partnership for Peace Information Management System (PIMS). ISN is one of Switzerland's contributions to the Partnership for Peace. Its focus is primarily on developing Internet support tools for civilian organisations, both non-governmental and quasi-governmental, engaged in the study and practice of security policy. During the conference, a prototype website for the Consortium was demonstrated on PIMS. This work will be refined by a conference-commissioned working group to be conducted under joint Swiss-US leadership. The users, in collaboration with an information technology working group of the Consortium, should further develop character and content of these electronic tools. It was the view of many of the participants that exploitation of technology as part of the Consortium effort was clearly secondary to the im- 
portance of interaction at the personal level between researchers, Defence Academies, and Security Studies Institutes.

The Consortium's unique and distinct character derives from the new approach of bringing defence academies and security studies institutes of all EAPC member countries together for enhanced exchange and co-operation. Within individual nations, cooperation between national security studies institutes and academies is well established, and internationally there is co-operation between academies on one hand and between security studies institutes on the other, but international exchange between these two groups appears to be limited. The Consortium is meant to bridge this gap and establish contacts between academies and institutes throughout the Euro-Atlantic region.

- Academies will improve the efficiency of education and training based on increased availability of accurate information from different sources in their own country, in the region of interest, and from external countries, thus helping to find a neutral and professional appreciation of a given security situation.

- Security studies institutes will be able to funnel their results directly into the education and training systems and can maintain mutually beneficial contacts with decision-makers. In addition, they will, similar to the academies, profit from the international exchange.

- Students in participating institutions will have the same broad scope of information available. They will also be able to share the results of their own studies and to discuss them via the Consortium network. Equally important, they will maintain access to the information sources as alumni and can utilize them in their later work.

Along the lines of this concept it should be possible to establish a meaningful and unique dialogue of institutes, academies, and alumni in support of an evolving EuroAtlantic security community. 